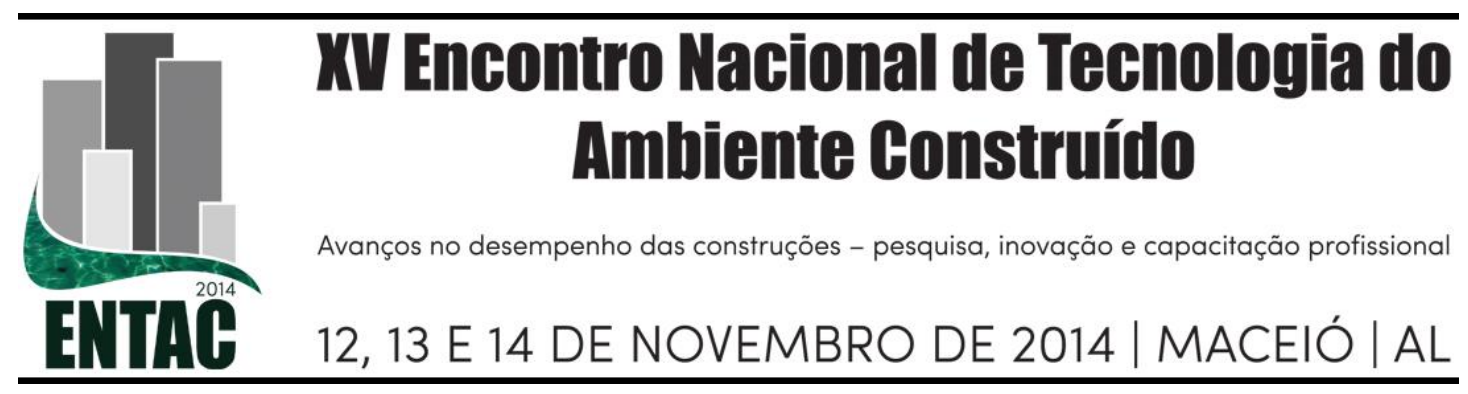

\title{
USOS FINAIS DE ÁGUA EM HABITAÇÕES DE INTERESSE SOCIAL NO SUL DO BRASIL
}

\author{
MARINOSKI, Ana Kelly (1); SILVA, Arthur Santos (2); VIEIRA, Abel Silva (3); \\ GHISI, Enedir (4)
}

Universidade Federal de Santa Catarina, Departamento de Engenharia Civil, Laboratório de Eficiência Energética em Edificações

(1) anakmarinoski@gmail.com (2) arthurssilva07@gmail.com (3) sv.abel@gmail.com (4) enedir@labeee.ufsc.br

\begin{abstract}
RESUMO
O conhecimento dos padrões de uso da água em edificações é essencial para planejar eficazmente as necessidades de melhorias e incentivar ações de racionalização do uso da água. Este artigo tem por objetivo caracterizar o consumo e estimar os usos finais de água em uma amostra de 48 habitações de interesse social, localizadas na região de Florianópolis-SC. Os dados foram coletados através de aplicação de questionários com os moradores das residências participantes da pesquisa e medição da vazão de água dos aparelhos sanitários existentes. Os resultados obtidos indicaram que o chuveiro foi o aparelho sanitário responsável pela maior parcela de consumo de água nas residências, representando 33\% do total dos usos finais médios. As famílias com renda de até três salários mínimos consumiram em média $152 \mathrm{~L} / \mathrm{hab}$.dia, enquanto famílias com renda entre três e cinco salários mínimos, $111 \mathrm{~L} / \mathrm{hab}$.dia. As famílias com renda acima de cinco salários mínimos consumiram em média $113 \mathrm{~L} / \mathrm{hab}$.dia. Os dados obtidos neste estudo poderão ser utilizados para aperfeiçoar a previsão da demanda futura e desenvolver programas de conservação da água nesta tipologia de edificação.
\end{abstract}

Palavras-chave: padrões de consumo de água, usos finais de água, características socioeconômicas, habitações de interesse social.

\begin{abstract}
Knowing water consumption patterns in buildings is a key information for planning the needs of improvement and to encourage water conservation measures. This article aims to characterize the water consumption pattern and end-uses in low-income houses in the region of Florianópolis-SC. Data were collected by interviewing householders, as well as by measuring the flow rate of existing water fixtures and appliances. The results indicated that the shower was the fixture with the largest water consumption in households, i.e., about $33 \%$ of total water consumption on average. Households with incomes up to three minimum wages consumed $152 \mathrm{~L} /$ capita.day on average; while households with income between three and five minimum wages, $111 \mathrm{~L}$ capita.day. Households with incomes over five minimum wages consumed 113 L/capita.day of water on average. The results of this study can be used to estimate the consumption of water for new buildings as well as to develop integrated water management strategies in low income developments in Florianópolis.
\end{abstract}

Keywords: water consumption pattern, water end-uses, socioeconomic characteristics, low-income houses.

\section{INTRODUÇÃO}

O desenvolvimento de estratégias eficientes para reduzir o consumo de água está vinculado à caracterização dos usos finais de água. A partir deste conhecimento é possível avaliar os principais aparelhos responsáveis pelo uso da água e priorizar o 
desenvolvimento de tecnologias para se gerar uma maior economia efetiva (ROCHA et al., 1998).

Além disso, os usos finais de água são úteis para que possam ser caracterizadas e avaliadas ações para a redução da demanda de água e desperdícios gerados nas habitações, bem como as possíveis fontes alternativas de água. Também são essenciais para a identificação da parcela da demanda total que pode ser economizada através de fontes alternativas de água (WILLIS et al., 2013).

Cada população, região, país apresenta padrões de consumo de água próprios; assim, o levantamento de usos finais específicos em cada estudo é decisivo para a previsão da demanda de água (INMAN; JEFFREY, 2006). As ações de gestão da demanda e uso racional de água são mais eficientes de acordo com o público a que se destinam. Por isso, conhecer os fatores que interferem na demanda por água de comunidades de interesse social, qual a sua percepção sobre a situação da água e a necessidade de usá-la de forma consciente, permitirá estabelecer estratégias para implementação de uso racional para esta parcela da população (GARCIA et al., 2010).

Com o aumento do poder aquisitivo das populações de baixa renda poderá ocorrer uma elevação da demanda de água nas cidades. Com o desenvolvimento de novas políticas públicas habitacionais, o uso racional de água em habitações de interesse social tem potencial para reduzir a demanda nos sistemas públicos de água e esgoto. Deste modo, a caracterização do consumo de água nessas habitações pode ser uma medida importante para promover a economia de água potável em escala urbana.

No entanto, são escassos os estudos que apresentam dados de usos finais de água em habitações de interesse social. No Brasil, na região metropolitana de Salvador, Bahia, Cohim et al. (2009) avaliaram os usos finais de água em dez residências de baixa renda. Os resultados da pesquisa indicaram que ocorre maior consumo na pia da cozinha (29\%), seguido da bacia sanitária $(23 \%)$ e do chuveiro (21\%). A lavanderia e o lavatório representaram $17 \%$ e $10 \%$ do consumo de água, respectivamente. A renda familiar verificada era de até dois salários mínimos, sendo que a maioria (78\%) possuía renda de até um salário mínimo. O consumo de água por habitante variou entre 74,3 e 86,0 L/hab.dia, com média de aproximadamente 80,0 L/hab.dia.

Em outro estudo, Ywashima et al. (2006) caracterizaram o uso de água em 27 residências unifamiliares de interesse social localizadas na cidade de Paulínia, São Paulo. Observouse que o consumo mensal de água nas residências investigadas variou de 3 a $25 \mathrm{~m}^{3} / \mathrm{mês}$, enquanto o indicador de consumo variou de 46 a $309 \mathrm{~L} / \mathrm{hab}$.dia. Os valores médios obtidos de consumo mensal e consumo per capita foram $12 \mathrm{~m}^{3}$ e 113 L/hab.dia, respectivamente.

Dantas et al. (2006) analisaram os hábitos de consumo de água em 19 residências unifamiliares de interesse social em Itajubá, Minas Gerais. Os dados foram coletados através de entrevistas com os usuários. O indicador de consumo médio encontrado foi de $117 \mathrm{~L} /$ hab.dia (variando de 80 a $133 \mathrm{~L} / \mathrm{hab}$.dia), correspondendo a um consumo médio de $11,6 \mathrm{~m}^{3} / \mathrm{mês}$.

No cenário internacional são raros estudos abordando os usos finais de água em residências de interesse social. A maioria dos estudos existentes avalia o consumo de água em residências unifamiliares e multifamiliares de médio padrão (GHISI; OLIVEIRA, 2007; GHISI; FERREIRA, 2006; LEE et al., 2012; BEAL et al., 2013; MATOS et al., 2013). Portanto, nota-se que ainda são poucos os estudos sobre consumo de água que apresentam os usos finais e consumo de água per capita em habitações de interesse social. 
Assim, torna-se necessário investigar os padrões de consumo de água em conjunto com os dados socioeconômicos nessa tipologia de edificação.

\section{OBJETIVO}

Este artigo tem como objetivo caracterizar o consumo de água e estimar os usos finais de água em habitações de interesse social localizadas na região da Grande Florianópolis, sul do Brasil.

\section{MÉTODO}

O consumo de água e os usos finais foram avaliados por meio de pesquisas de campo, ou seja, entrevistas com membros das famílias e análise de aparelhos sanitários. As entrevistas foram realizadas com objetivo de determinar a duração e a frequência de uso de cada aparelho ou equipamento, bem como coletar informações sobre o histórico de consumo mensal de água registrado pela concessionária de água local. A análise dos aparelhos foi realizada para determinar tanto a vazão de chuveiros e torneiras, quanto o consumo de água por ciclo de lavadoras de roupas e bacias sanitárias.

\subsection{Análise socioeconômica}

As residências avaliadas são habitações de interesse social localizadas na região de Florianópolis, Santa Catarina, região sul do Brasil como mostra a Figura 1.

\section{Figura 1 - Localização das residências avaliadas}

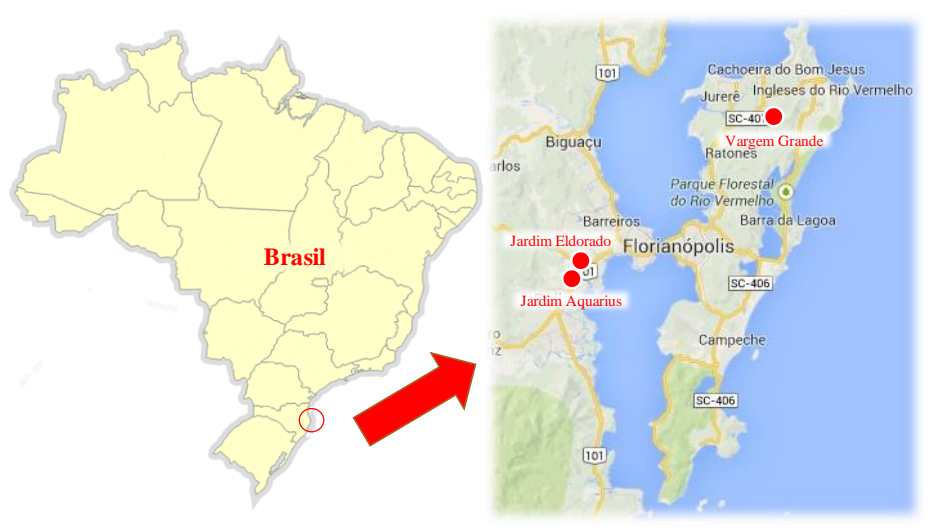

Esta etapa da pesquisa utilizou dados obtidos em levantamentos realizados pela Rede de Pesquisa 22 da Financiadora de Estudos e Projetos - FINEP - financiada dentro da Chamada Pública Saneamento Ambiental e Habitação do edital 07/2009. A referida rede tem como foco de estudo "Uso racional de água e eficiência energética em habitações de interesse social".

Fonte: Do Autor (2014)

As famílias moradoras nas habitações selecionadas para o estudo atenderam ao menos um dos seguintes critérios: (i) Preferencialmente, possuir renda familiar igual ou inferior a 3 salários mínimos ( 3 x R \$ 622,00 = R \$ 1,866,00 - abril de 2012); (ii) Residir em área de interesse social (ex.: área de interesse social (favelas) ou rua com diversas residências de baixa renda); (iii) Possuir residência financiada pelo programa Minha Casa Minha Vida (BRASIL, 2011) ou outro programa habitacional público para famílias de baixa renda.

\subsection{Caracterização dos usos finais de água}

Os usos finais de água foram determinados por meio de entrevistas com aplicação de questionários aos moradores das residências para determinar a frequência e o tempo de utilização dos aparelhos sanitários. Para equipamentos e aparelhos usados em base diária, os moradores foram convidados a descrever o padrão de consumo horário e estimar a frequência média de eventos ou duração total de uso em cada hora do dia. Para 
equipamentos e aparelhos usados em base semanal ou mensal, os moradores estimaram a respectiva frequência de utilização por semana ou mês.

Além disso, a vazão e o consumo de água por ciclo para cada aparelho foi determinada através de uma avaliação in loco. As vazões de água habituais foram calculadas solicitando-se às famílias que abrissem as torneiras e os chuveiros três vezes nas vazões típicas usadas, e em seguida através da medição do volume total ao longo de 10 segundos para cada um dos três eventos. A partir das três vazões medidas, uma vazão média foi calculada. Além disso, informações sobre o consumo de água por ciclo de lavadoras de roupa e bacias sanitárias com caixa de descarga foi obtido a partir das especificações técnicas do produto ou no catálogo do Programa de Eficiência Energética Brasileira (PROCEL, 2012). A vazão das bacias sanitárias com válvula de descarga foi considerada igual a 1,7 L/s de acordo com norma brasileira NBR 5626 (ABNT, 1998).

O consumo mensal de água em cada aparelho foi calculado multiplicando-se ou sua respectiva vazão média e tempo de uso total estimado por mês, ou seu respectivo consumo médio de água por ciclo e estimativa do número de eventos por mês, de acordo com a Eq. 1.

$$
C=Q \times t=c \times F
$$

onde: $\quad \mathrm{C}=$ consumo mensal de água $\left(\mathrm{m}^{3} / \mathrm{mês}\right)$;

$\mathrm{Q}=$ vazão média $(\mathrm{L} / \mathrm{s})$;

$\mathrm{t}=$ tempo total de utilização (segundos/mês);

$\mathrm{c}=$ consumo de água por ciclo (L/ciclo);

$\mathrm{F}=$ frequência de uso (ciclo/mês).

A estimativa do consumo de água em bacias sanitárias com válvula de descarga foi calculada multiplicando-se a vazão de água deste aparelho indicada pela NBR 5626 (ABNT, 1998) pelo tempo médio de uso da válvula de descarga nas residências.

Para representar os usos finais de água, os resultados foram apresentados como médias com intervalo de confiança de $90 \%$. O intervalo de confiança foi calculado usando a distribuição t de Student, considerando um grau de liberdade igual ao tamanho da amostra menos um (isto é, n-1). Os cálculos foram realizados utilizando o programa computacional Minitab 16 (2010). Os intervalos de confiança foram determinados também para cada faixa de renda estudada. Usos finais de água foram classificados em potável (pia de cozinha, lavatório e chuveiro) e não potável (bacias sanitárias, tanque, torneira externa e lavadora de roupas).

\section{RESULTADOS}

\subsection{Características socioeconômicas das famílias}

As características socioeconômicas das famílias pesquisadas estão ilustradas na Figura 2. A renda familiar mensal máxima verificada foi igual a $\mathrm{R} \$ 8000,00$, enquanto a renda per capita máxima foi igual a $\mathrm{R} \$ 4000,00$. Estes valores máximos são valores considerados discrepantes porque os valores médios são consideravelmente mais baixos, próximos de $\mathrm{R} \$ 4100,00$ para a renda total, e de $\mathrm{R} \$ 1000,00$ para a renda per capita, para a faixa de renda 3 . O número de ocupantes variou de um a seis moradores por residência, sendo que o número mediano verificado foi de quatro moradores. A mediana da renda familiar é de aproximadamente $R \$ 2000,00$ e a mediana da renda per capita é de aproximadamente $R \$$ 650,00 
Figura 2 - Características socioeconômicas da amostra
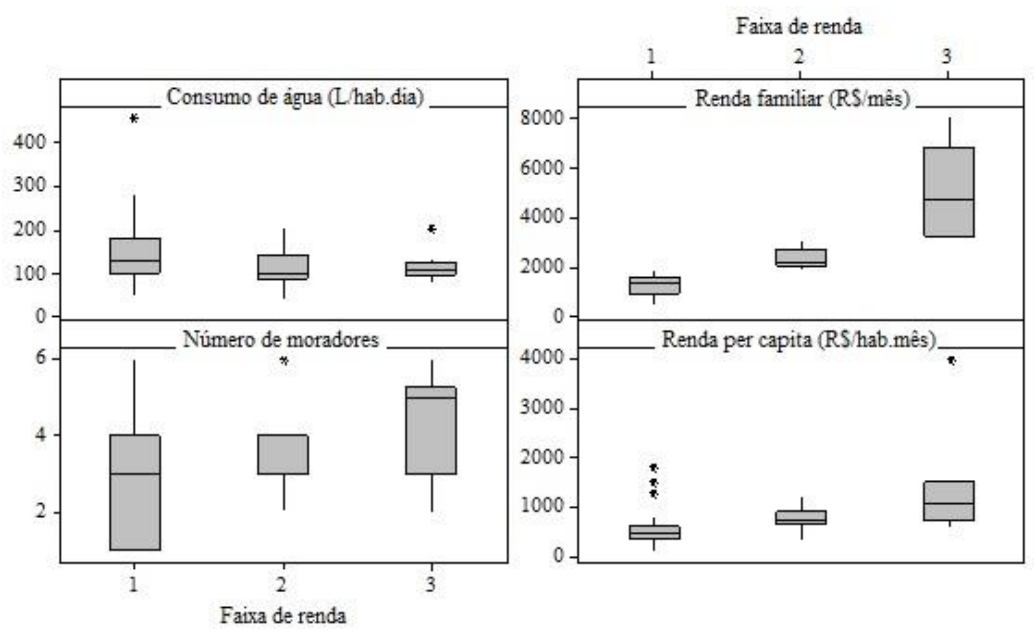

Entre as diferentes faixas de renda, podese notar que o número médio de ocupantes aumenta com a renda familiar. O consumo de água tem uma amplitude mais elevada na primeira faixa de renda. A própria renda familiar tem maior amplitude na terceira faixa de renda.

Fonte: Do Autor (2014)

\subsection{Aparelhos sanitários existentes}

As residências avaliadas estavam equipadas com os seguintes aparelhos sanitários: pia de cozinha, chuveiro, bacia sanitária, lavatório, lavadora de roupas, torneira externa e tanque. Entre as famílias estudadas, $77 \%$ possuíam lavadora de roupas, $45 \%$ apresentaram bacia sanitária com caixa de descarga (caixa acoplada ou caixa suspensa), e 55\% das residências apresentou bacias sanitárias com válvula de descarga. Além disso, apenas 30\% das residências usam água para usos finais externos, como irrigação e lavagem do carro.

\subsection{Padrão de consumo de água}

O consumo de água nas 48 famílias estudadas foi igual a 132,3 L/hab.dia. A Figura 3 ilustra o total e os padrões de consumo de água per capita, bem como a classificação de renda (faixas de renda 1, 2 e 3), para as residências estudadas.

Figura 3 - Padrões de consumo de água e classificação de renda nas residências.

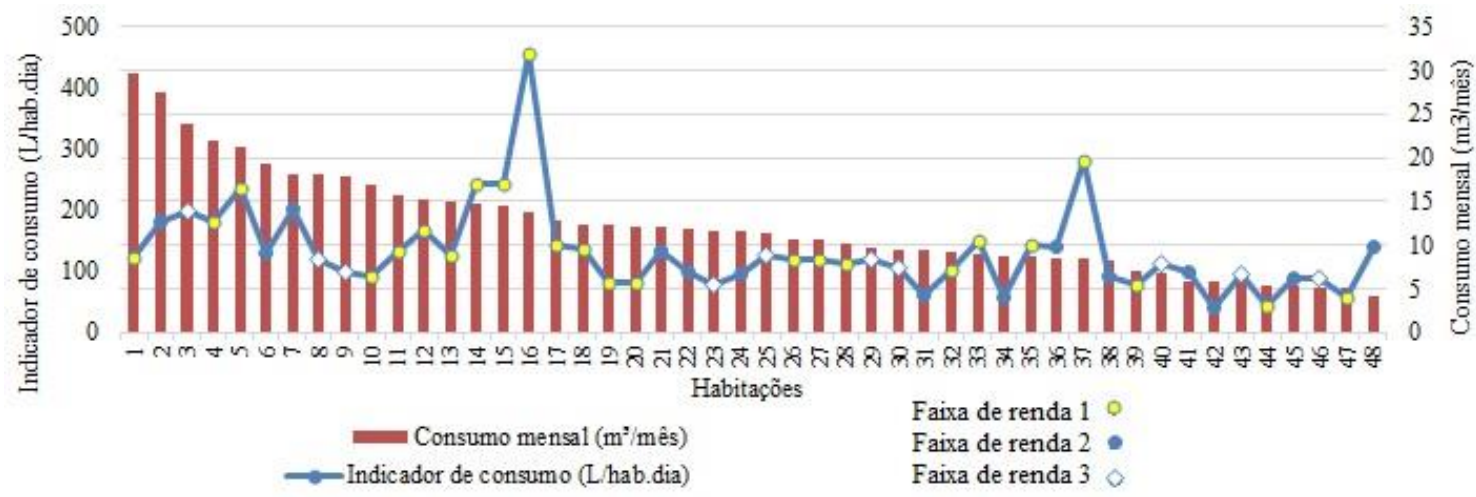

Fonte: Do Autor (2014)

Em geral, o consumo total de água estava relacionado com o padrão de ocupação da residência, no qual quanto maior o tempo da permanência dos moradores em casa, maior era o consumo de água. Resultados semelhantes foram descritos por Vieira (2012) para famílias de baixa renda em Florianópolis. Em 33\% das residências avaliadas o consumo total mensal de água foi de até $10 \mathrm{~m}^{3}$. Essas famílias não têm nenhum incentivo econômico para reduzir o seu consumo de água ou utilizar fontes alternativas, pois a 
companhia de água local cobra uma taxa fixa para o consumo total de água, igual a 10 $\mathrm{m}^{3} / \mathrm{mês}$ por residência. A Figura 4 mostra que não existe uma correlação entre o consumo de água e a renda familiar para a amostra estudada.

Figura 4 - Correlação entre o consumo médio de água per capita e renda das famílias.
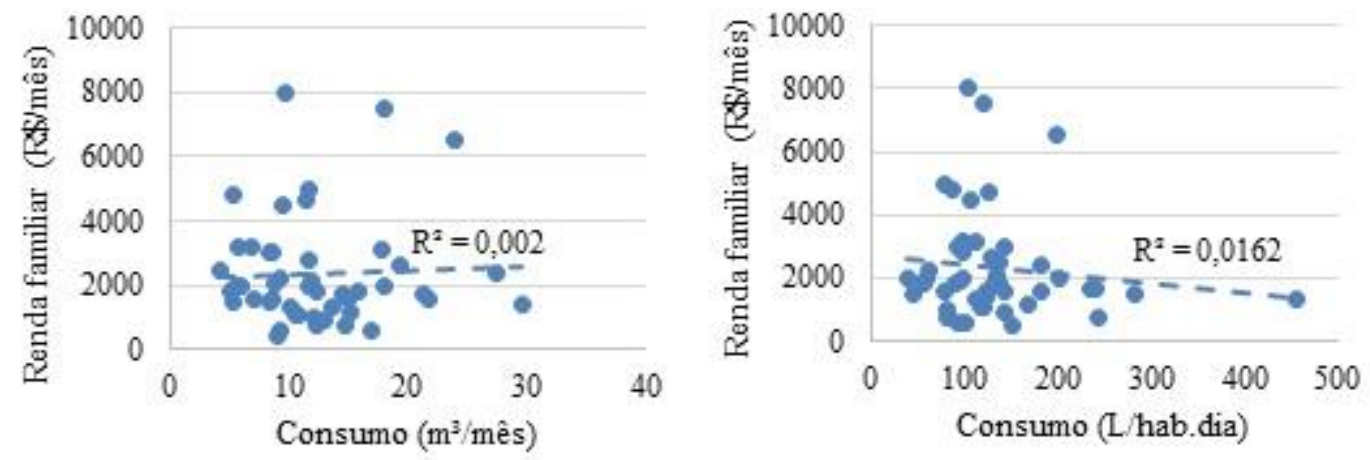

Fonte: Do Autor (2014)

Para a faixa de renda de até três salários mínimos, houve uma diferença de $410 \mathrm{~L} / \mathrm{hab}$.dia entre as habitações; para a faixa de renda de três a cinco salários mínimos, a diferença foi de $162 \mathrm{~L} /$ hab.dia entre as habitações. Acima de cinco salários mínimos, a diferença foi de $121 \mathrm{~L} / \mathrm{hab}$.dia. Essas diferenças indicam a heterogeneidade da amostra, apesar da divisão dos dados pelas condições financeiras das famílias. Para a faixa de renda de até três salários, por exemplo, há grande amplitude de variação no consumo per capita. Padrões similares de consumo de água são descritos em outros estudos realizados no Brasil (DANTAS et al., 2006; YWASHIMA et al., 2006; VIEIRA, 2012).

\subsection{Usos finais de água}

Por meio de medição in loco nos aparelhos hidráulicos foi determinada a vazão de chuveiros e torneiras, conforme apresentado na Tabela 1 . O consumo de água por ciclo estimado para lavadora de roupas e bacias sanitárias é mostrado na Tabela 2.

Tabela 1 - Vazão de água dos aparelhos sanitários.

\begin{tabular}{|c|c|c|}
\hline \multirow[b]{2}{*}{ Equipamento } & \multicolumn{2}{|c|}{ Vazão (L/s) } \\
\hline & Média & $\begin{array}{l}\text { Desvio } \\
\text { padrão }\end{array}$ \\
\hline Chuveiro & 0,07 & 0,03 \\
\hline Lavatório & 0,08 & 0,04 \\
\hline Pia & 0,09 & 0,05 \\
\hline Tanque & 0,13 & 0,13 \\
\hline Torneira externa & 0,17 & 0,11 \\
\hline
\end{tabular}

Tabela 2 - Consumo de água por ciclo em aparelhos sanitários.

\begin{tabular}{l|c|c}
\hline \multirow{2}{*}{ Equipamento } & \multicolumn{2}{|c}{ Consumo de água (L/ciclo) } \\
\cline { 2 - 3 } & Média & $\begin{array}{c}\text { Desvio } \\
\text { padrão }\end{array}$ \\
\hline $\begin{array}{l}\text { Bacia sanitária com } \\
\text { válvula de descarga }\end{array}$ & 6,2 & 1,4 \\
\hline $\begin{array}{l}\text { Bacia sanitária com } \\
\text { caixa acoplada }\end{array}$ & 11,5 & 2,6 \\
\hline Lavadora de roupas & 102,5 & 50,2 \\
\hline
\end{tabular}

A vazão dos aparelhos sanitários variou significativamente entre as residências estudadas (Tabela 1). Essa variação foi maior para os usos finais que geralmente são operados em suas vazões máximas, ou seja, tanque e torneira externa. As vazões médias para estes equipamentos foram altas, 0,13 e $0,17 \mathrm{~L} / \mathrm{s}$, respectivamente, como são normalmente operados em sua capacidade máxima, a fim de realizar de forma mais rápida a função pretendida (por exemplo, encher um balde ou regar as plantas). Portanto, a vazão destes dois aparelhos depende da capacidade máxima de fornecimento de água dos sistemas hidráulicos prediais de acordo com as suas características, incluindo: (i) fornecimento 
urbano de água direto ou indireto; (ii) perda de carga nos componentes hidráulicos; (iii) tipo de torneira. Uma tendência semelhante foi observada para o consumo de água por ciclo dos aparelhos sanitários (Tabela 2). Tal parâmetro apresentou variação maior para lavadora de roupas, pois o seu volume é diretamente proporcional ao tipo de lavadora, modelo e ciclo de lavagem utilizado.

A Tabela 3 mostra o indicador mensal do consumo de água per capita para cada aparelho, onde a média e os limites superior e inferior são apresentados para as três faixas de renda. Por exemplo, a lavadora de roupas, na faixa de renda 1 , teve um consumo médio de água e limite inferior e superior de 23,0, 11,9 e 34,0 L/hab.dia, respectivamente. A Tabela 4 mostra a média e o limite superior e inferior para o consumo de água diário em aparelhos sanitários. A Figura 5 mostra os usos finais de água para cada família avaliada.

\section{Tabela 3 - Consumo médio de água per capita, limite inferior e superior por aparelho sanitário.}

\begin{tabular}{l|c|c|c|c|c|c|c|c|c}
\hline \multirow{2}{*}{ Equipamento } & \multicolumn{3}{|c|}{ Renda 1 (L/hab.dia) } & \multicolumn{3}{c|}{ Renda 2 (L/hab.dia) } & \multicolumn{3}{c}{ Renda 3 (L/hab.dia) } \\
\cline { 2 - 10 } & $\begin{array}{c}\mathbf{L I}^{*} \\
\mathbf{9 0 \%}\end{array}$ & Média & $\begin{array}{c}\mathbf{L S}^{* *} \\
\mathbf{9 0 \%}\end{array}$ & $\begin{array}{c}\mathbf{L I}^{*} \\
\mathbf{9 0 \%}\end{array}$ & Média & $\begin{array}{c}\mathbf{L S}^{* *} \\
\mathbf{9 0 \%}\end{array}$ & $\begin{array}{c}\mathbf{L I}^{*} \\
\mathbf{9 0 \%}\end{array}$ & Média & $\begin{array}{c}\mathbf{L S}^{* *} \\
\mathbf{9 0 \%}\end{array}$ \\
\hline Chuveiro & 58,5 & 79,4 & 100,3 & 33,7 & 53,7 & 73,7 & 27,1 & 39,7 & 52,3 \\
\hline Bacia sanitária & 37,5 & 46,0 & 54,5 & 19,7 & 25,4 & 31,2 & 11,8 & 19,5 & 27,2 \\
\hline Pia & 35,0 & 45,1 & 55,3 & 15,1 & 22,6 & 30,1 & 12,9 & 19,3 & 25,6 \\
\hline Lavadora de roupas & 11,9 & 23,0 & 34,0 & 4,7 & 20,9 & 37,0 & 3,9 & 7,2 & 10,5 \\
\hline Lavatório & 5,3 & 7,8 & 10,4 & 3,8 & 7,1 & 10,4 & 0,0 & 1,0 & 2,0 \\
\hline Tanque & 2,4 & 6,1 & 9,8 & 0,8 & 2,3 & 3,9 & 0,4 & 0,9 & 1,4 \\
\hline Outros & 1,9 & 3,3 & 4,7 & 0,2 & 0,5 & 0,9 & 1,0 & 1,9 & 2,8 \\
\hline Torneira externa & 0,7 & 2,3 & 3,9 & 0,1 & 1,2 & 2,3 & 2,3 & 5,8 & 9,2 \\
\hline
\end{tabular}

Fonte: Do Autor (2014). "LI é o limite inferior da média com $90 \%$ de confiabilidade; ${ }^{* *}$ LS é o limite superior da média com $90 \%$ de confiabilidade.

Tabela 4 - Consumo médio diário de água, limite inferior e superior por aparelho sanitário.

\begin{tabular}{l|c|c|c|c|c|c|c|c|c}
\hline \multirow{2}{*}{ Equipamento } & \multicolumn{3}{|c|}{ Renda 1 (L/dia) } & \multicolumn{3}{c|}{ Renda 2 (L/dia) } & \multicolumn{3}{c}{ Renda 3 (L/dia) } \\
\cline { 2 - 11 } & $\begin{array}{c}\text { LI } \\
\mathbf{9 0 \%}\end{array}$ & Média & $\begin{array}{c}\mathbf{L S}^{* *} \\
\mathbf{9 0 \%}\end{array}$ & $\begin{array}{c}\mathbf{L I}^{*} \\
\mathbf{9 0 \%}\end{array}$ & Média & $\begin{array}{c}\mathbf{L S}^{* *} \\
\mathbf{9 0 \%}\end{array}$ & $\begin{array}{c}\mathbf{L I}^{*} \\
\mathbf{9 0 \%}\end{array}$ & Média & $\begin{array}{c}\mathbf{L S}^{* * *} \\
\mathbf{9 0 \%}\end{array}$ \\
\hline Chuveiro & 127,8 & 148,4 & 169,0 & 103,2 & 147,8 & 192,3 & 108,8 & 163,4 & 218,0 \\
\hline Bacia sanitária & 83,2 & 96,8 & 110,5 & 63,5 & 78,6 & 93,7 & 48,7 & 88,4 & 128,0 \\
\hline Pia & 80,5 & 99,8 & 119,2 & 45,1 & 65,1 & 85,2 & 59,9 & 70,4 & 80,9 \\
\hline Lavadora de roupas & 45,8 & 63,2 & 80,7 & 25,7 & 69,5 & 113,3 & 16,4 & 38,8 & 61,2 \\
\hline Lavatório & 16,4 & 30,4 & 44,3 & 12,2 & 25,5 & 38,8 & 6,4 & 9,7 & 13,0 \\
\hline Tanque & 16,3 & 21,7 & 27,2 & 13,7 & 21,0 & 28,3 & 0,0 & 15,9 & 36,8 \\
\hline Torneira externa & 11,1 & 19,9 & 28,7 & 10,0 & 20,8 & 31,7 & 28,4 & 53,5 & 78,7 \\
\hline Outros & 4,9 & 8,8 & 12,8 & 0,8 & 2,0 & 3,1 & 4,4 & 9,1 & 13,7 \\
\hline
\end{tabular}

Fonte: Do Autor (2014). "LI é o limite inferior da média com $90 \%$ de confiabilidade; ${ }^{* *}$ LS é o limite superior da média com $90 \%$ de confiabilidade.

Os usos não potáveis (bacias sanitárias, tanque, torneira externa e lavadora de roupas) foram equivalentes em média $42-45 \%$ do consumo total de água nas residências. Todos estes usos não potáveis poderiam ser abastecidos por água pluvial como fonte alternativa de água. A água cinza produzida a partir de efluentes dos chuveiros, lavatórios e lavadora de roupas poderia fornecer $23-32 \%$ da demanda total de água nas habitações. Portanto, há um grande potencial de uso de água cinza como fonte alternativa de abastecimento de água em tanque, bacia sanitária e torneiras externas, pois a capacidade de fornecimento ultrapassa a demanda. 
Figura 5 - Usos finais médios de água na amostra de residências.

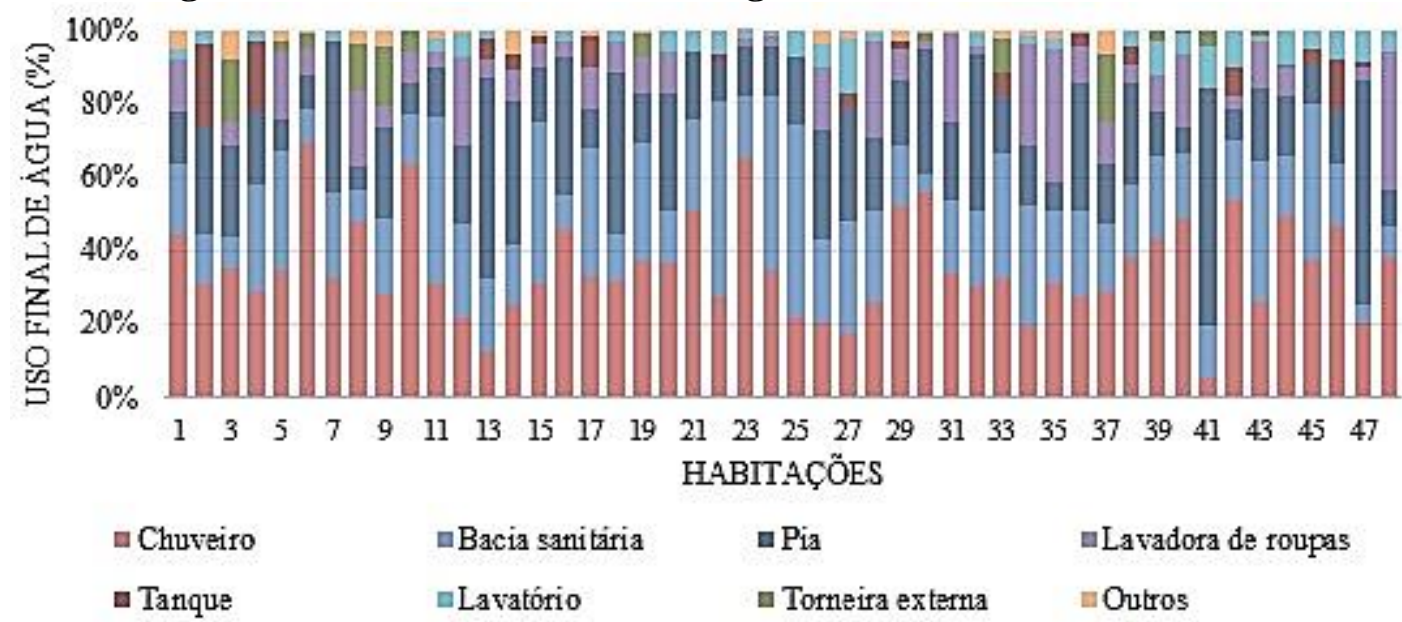

Fonte: Do Autor (2014)

A Tabela 5 apresenta os usos finais de água para cada aparelho e os limites do intervalo de confiança para cada faixa de renda. Em média, chuveiro e a bacia sanitária representam os maiores usos finais de água para todas as faixas de renda. No entanto, nas faixas de renda 1 e 3 , o terceiro maior uso final é a pia da cozinha; ainda, para a faixa de renda 2 , o terceiro maior uso final é a lavadora de roupas.

Tabela 5 - Usos finais de água médios, limites inferiores e superiores com $90 \%$ de confiabilidade.

\begin{tabular}{l|c|c|c|c|c|c|c|c|c}
\hline \multirow{2}{*}{ Equipamento } & \multicolumn{3}{|c|}{ Renda 1 (\%) } & \multicolumn{3}{c|}{ Renda 2 (\%) } & \multicolumn{3}{c}{ Renda 3 (\%) } \\
\cline { 2 - 11 } & $\begin{array}{c}\text { LI* } \\
\mathbf{9 0 \%}\end{array}$ & Média & $\begin{array}{c}\text { LS } \\
\mathbf{9 0 \%}\end{array}$ & $\begin{array}{c}\text { LI* } \\
\mathbf{9 0 \%}\end{array}$ & Média & $\begin{array}{c}\text { LS }^{* *} \\
\mathbf{9 0 \%}\end{array}$ & $\begin{array}{c}\text { LI }^{*} \\
\mathbf{9 0 \%}\end{array}$ & Média & $\begin{array}{c}\text { LS }^{* * *} \\
\mathbf{9 0 \%}\end{array}$ \\
\hline Chuveiro & 26 & 30 & 35 & 24 & 34 & 45 & 24 & 36 & 49 \\
\hline Bacia sanitária & 17 & 20 & 23 & 15 & 18 & 22 & 11 & 20 & 29 \\
\hline Pia & 16 & 20 & 24 & 10 & 15 & 20 & 13 & 16 & 18 \\
\hline Lavadora de roupas & 9 & 13 & 16 & 6 & 16 & 26 & 4 & 9 & 14 \\
\hline Tanque & 3 & 6 & 9 & 3 & 6 & 9 & 1 & 2 & 3 \\
\hline Lavatório & 3 & 4 & 6 & 3 & 5 & 7 & 0 & 4 & 8 \\
\hline Torneira externa & 2 & 4 & 6 & 2 & 5 & 7 & 6 & 12 & 18 \\
\hline Outros & 1 & 2 & 3 & 0 & 0 & 1 & 1 & 2 & 3 \\
\hline
\end{tabular}

Fonte: Do Autor (2014). "LI é o limite inferior da média com $90 \%$ de confiabilidade; ${ }^{* *}$ LS é o limite superior da média com $90 \%$ de confiabilidade.

Os chuveiros foram os aparelhos com maior consumo de água entre as famílias, em média 30 a 36\%, variando entre 24 a $49 \%$ no limite inferior e superior com $90 \%$ de confiabilidade. $\mathrm{O}$ segundo maior equipamento consumidor de água a bacia sanitária de 11 a 29\%, seguido de pia da cozinha, de 10 a 24\%. Em média de 67 a $72 \%$ do consumo de água nas famílias de baixa renda estudadas é destinado para estes três maiores usos finais. No entanto, a contribuição de cada aparelho para o consumo total de água variou consideravelmente entre as residências.

Utilizando-se intervalos de confiança, estimou-se a variabilidade do padrão de consumo de água para cada aparelho. Por exemplo, o uso de chuveiro em famílias classificadas na faixa de renda 1 representou, em média, $30 \%$ do consumo de água, que varia entre $26 \%$ e $35 \%$, com um intervalo de confiança de $90 \%$. Pia de cozinha e bacia sanitária apresentaram padrões de consumo mensal de água relativamente semelhantes. 


\section{CONCLUSÕES}

Este artigo caracterizou o padrão de consumo de água e os usos finais de água em uma amostra de 48 residências de baixa renda na região metropolitana de Florianópolis-SC.

Os resultados indicaram que o chuveiro foi o aparelho sanitário responsável pela maior parcela do consumo de água nas residências. O padrão de consumo de água foi associado ao padrão de ocupação das residências, onde se constatou que quanto maior o tempo de permanência dos moradores nas residências, maior era o consumo de água.

Com base na análise de usos finais de água, foi possível investigar a demanda de água não potável das habitações em conjunto com os respectivos dados socioeconômicos das famílias analisadas. Constatou-se que houve diferença de até $26 \%$ de consumo médio de água per capita entre as diferentes faixas de renda avaliadas. Padrões similares de consumo de água per capita foram encontrados em outros estudos brasileiros. As famílias com renda de até três salários mínimos consumiram em média $152 \mathrm{~L} /$ hab.dia enquanto, famílias com renda entre três e cinco salários mínimos, $111 \mathrm{~L} /$ hab.dia. As famílias com renda acima de cinco salários mínimos consumiram em média 113 L/hab.dia.

Os resultados deste estudo podem ser usados para estimar o consumo de água para novas habitações, bem como a desenvolver estratégias integradas de gestão da água em empreendimentos de baixa renda em Florianópolis. Esses dados também podem ser utilizados para campanhas de sensibilização sobre práticas de conservação de água entre famílias de baixa renda.

\section{AGRADECIMENTOS}

Agradecimentos à FINEP pelo apoio e financiamento do estudo.

\section{REFERÊNCIAS}

ASSOCIAÇÃO BRASILEIRA DE NORMAS TÉCNICAS (ABNT). NBR 5626: Instalação predial de água fria. Rio de Janeiro. 1998.

BEAL. C, STEWART, R.A., FIELDING, K. A novel mixed method smart metering approach to reconciling differences between perceived and actual residential end use water consumption. Journal of Cleaner Production, v. 2013, n. 0, p. 116-128, 2013.

BRASIL. Ministério das Cidades. Secretaria Nacional de Habitação, Gabinete da Secretaria. Programa Minha Casa, Minha Vida (PMCMV). Medida Provisória $\mathrm{n}^{\circ}$ 514, de 2010, Destaques, Brasília, DF, 2011.

COHIM, E.; GARCIA, A. P. A.; KIPERSTOK, A.; DIAS, M. Consumo de água em residências de baixa renda - estudo de caso. In: $25^{\circ}$ Congresso Brasileiro de Engenharia Sanitária e Ambiental, 2009, Recife. $25^{\circ}$ Congresso Brasileiro de Engenharia Sanitária e Ambiental. Rio de Janeiro - ABES.

DANTAS, C. T.; UBALDO JR., L.; POTIER, A. C.; ILHA, M. S. O. Caracterização do uso de água em residências de interesse social em Itajubá. XI Encontro Nacional de Tecnologia do Ambiente Construído, Florianópolis - SC, Anais... CD Rom, 2006.

GARCIA, A.P.A.; SANTOS, M.; CONCEIÇÃO, D.; MACHADO, A.; KIPERSTOK, A. Consumo domiciliar e uso racional da água em áreas de baixa renda: pesquisa de opinião. In: I Congresso Baiano de Engenharia Sanitária e Ambiental - COBESA, Salvador, 2010.

GHISI, E.; FERREIRA, D.F. Potential for Potable Water Savings by Using Rainwater and Greywater in a Multi-storey Residential Building in Southern Brazil. Building and Environment, v. 42, n. 7, p. 2512-2522, 2006. 
GHISI, E.; OLIVEIRA, S.M. Potential for potable water savings by combining the use of rainwater and greywater in houses in southern Brazil. Building and Environment, v 42, n. 4, p. 1731-1742, 2007.

INMAN, D.; JEFFREY, P. A review of residential water conservation tool performance and influences on implementation effectiveness. Urban Water Journal, v. 3, n. 3, p. 127-143, Taylor \& Francis, 2006.

LEE, D.-J., PARK, N-S; JEONG, W. End-use analysis of household water by metering: the case study in Korea. Water and Environment Journal, v. 26, p. 455-464, 2012.

MATOS, C.; TEIXEIRA, C. A.; DUARTE, A.A.L.S.; BENTES, I. Domestic water uses: Characterization of daily cycles in the north region of Portugal. Science of the Total Environment, 458-460, 444-450, 2013.

MINITAB. Minitab 16 Statistical Software. State College, PA: Minitab, 2010. Disponível em: (<www.minitab.com〉) Acesso em: março de 2013.

PROCEL. Programa Nacional de Conservação de Energia Elétrica. Disponível em: (<http://www.eletrobras.com>) Acesso em: abril de 2012.

ROCHA, A.L.; BARRETO, D.; IOSHIMOTO, E. Caracterização e monitoramento do consumo predial de água. Programa Nacional de Combate ao Desperdício de Água - Documento Técnico de Apoio № E1. Brasília: Ministério do Planejamento e Orçamento, 1998.

VIEIRA, A.S. Uso racional de água em habitações de interesse social como estratégia para a conservação de energia em Florianópolis, Santa Catarina. Dissertação de Mestrado (Engenharia Civil). Universidade Federal de Santa Catarina, 2012.

WILLIS, R.M.; STEWART, R.A.; GIURCO, D.P.; TALEBPOUR, M.R.; MOUSAVINEJAD, A. End use water consumption in households: impact of socio-demographic factors and efficient devices. Journal of Cleaner Production, 1-9, 2013.

YWASHIMA, L.A.; CAMPOS, M.A.S.; PIAIA, E.; LUCA, D.M.P.; ILHA, M.S.O. Caracterização do uso de água em residências de interesse social em Paulínia. XI Encontro Nacional de Tecnologia do Ambiente Construído, Florianópolis-SC, Anais... CD Rom, 2006. 